\title{
WORKING EFFICIENTLY WITH THE SERVICE INDUSTRIES
}

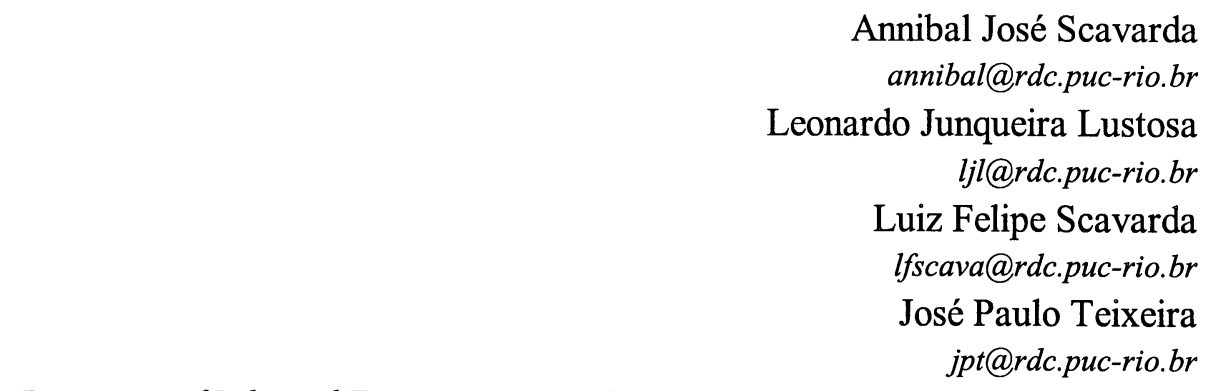

Department of Industrial Engineering - Pontificia Universidade Católica do Rio de Janeiro,

BRAZIL

\begin{abstract}
This paper intends to underline the virtual infrastructures and developments of the service industry. This study is based on the tourism industry, since this service industry is growing very fast all around the world. The paper presents the tourism environment, suggests the application of the yield management technique and discusses the necessity of the development of this industry in a virtual chain. The main goal of the paper is to study these subjects to help to stimulate all the organizations involved within the tourism industry or even within the service industry in order to make them work efficiently.
\end{abstract}

\section{INTRODUCTION}

The process of globalization of the human business has been studied thoroughly. Although the economic aspects have been widely analyzed, some other aspects that are deeply interwoven with economy need special attention. The dramatic change on wide spread computer power and telecommunication facilities allowed the development of a network of small firms that divided with the manufacturing world the responsibilities of production, supplier's interactions, goods distribution, consumer marketing and several other functions that were previously part of the manufacturing industry main activities.

The growth to global scale of business increased the necessity of competitiveness. The big corporations, in a first moment, outsourced some of its internal missions, giving the opportunity to the birth of small firms with specific expertise. The network of these small firms offers, nowadays, several services to the society and is responsible for the large percentage of working positions. The social importance of the service sector do not prevent its need for fierce competition, and 
survival depends on the continue use and development of specific technologies and human resource preparation.

Within the service society, tourism is the fastest growing sector. The motivation of this paper is the study of the service society in its more important segment: the tourism industry.

The paper first discuses some general points of the service and tourism industries. Then it points out the yield management as an alternative technique to stimulate the development of the service industry. The next section presents the importance of using some developed concepts of the manufacturing industries, like the supply chain management, in the service industry and the new competitive model that changed from the conventional "business unit" to "virtual business unit". Some final considerations are given at the end of the paper.

\section{THE SERVICE INDUSTRY}

The service industry deals with intangible values, that means that it can have parameters that can not be easily seen, touched, smelled, heard or even tasted before the purchase. It is characterized by its output that cannot be inventoried, by its high customer contact, by its need of short response time and also by its labor intensive character.

Many aspects influence the services values, some are defined by people curiosity or wish of knowledge, some are influenced by specific groups and others are influenced by the emotional feelings. Some values are based either on conditional parameters, where temporary situations enhance different reasons to consume.

Consumers have many different reasons to buy a service, normally sold almost at the same time that it is produced. There are three stages that the service industry should pay attention to: the pre-purchase, the counter and the post-purchase phase (Kurtz and Clow, 1998). All these phases are important to achieve successfully a service.

The service industry is intensively commanded by the consumer and, so, understanding the consumer expectations is very important. This understanding means to be able to perceive consumer's feelings (if the consumer is happy or disappointed), his attractions to the service (if he is going to buy or not the service) and maybe the consumer mood (when the customer is in a bad humor, he tends to be less tolerant). If the expectations are not met, the consumer will be disappointed, but, if they are met or exceeded, he will become satisfied. The more they are exceeded, the more consumers become happy with the service and higher will be the probability that they will desire it again. Some offered services drive the customer to an over expectation about them; initially that is good because it will attract the consumer, but the problem is that he will probably get disappointed, he will not use the services and, even worse, he will also advise people to not use them.

It is not easy to control the service demand, its structure involves many parameters: internal, external and firm-produced factors. The internal factor involves personal needs and asks for past experiences and the involvement of the consumer, while external factor involves competitive options and the social contexts. The firm factor involves the firm's attitudes: promotions, pricing, distributions and alliances. 
It is important to emphasize that people and the environment (attractive decor, appealing smells, music and friendly service personnel) have strong influences.

The service industry also involves many other delicate points, like the quality evaluation. Quality is very subjective in an intangible product, the environment of services: the procedures, the way the personnel acts, and many other aspects of the service can be controlled; however, the final quality criterion will always be the consumer perception. The consumer perceived quality is not accurately predictable and it is particular to each consumer. Sometimes the responsiveness is more important to the client then simply the offer of the "best" service; the client wants to feel that the people involved are doing their best to serve him.

The service industry has to choose its level of complexity (the level of detail, to which the service is defined) and its level of divergence (the spread of services it offers and the numbers of ways that the services can be offered).

It is important to underline that the service industry tries to offer pleasurable services to the customer. The customer should not be in contact with any kind of conflict; the company should avoid that conflicts between the interest of the organization and the ones of its employees and clients produce deleterious effects on the clients experience.

\section{THE TOURISM INDUSTRY}

Tourism is the action of traveling with recreational rest or cultural objectives. It can be viewed as one of the most significant phenomena of the present days, for the sum of activity sections that it embraces and for the number of people on which it acts. Its growth acquires enormous proportions world wide. The tourism propitiates a better knowledge among the people and, virtually, it strengthens international relationships. It offers a series of typical services of an economy including hostelries, transports, restaurants, amusements etc., and requires important infrastructure - highways, airports, railroads, electricity, water provisioning, sewers and communications.

The tourism industry is growing very much and fast due to the world's new scenario: aging population, longer life expectancies, more female work force participation, increased time pressure and leisure time, higher per capita income, changing social and cultural values and technical advances.

The tourism industry became the object of a fierce international competition being already the largest industry in the world, still showing an immense potential and it is present in almost all regions around the world. Practically everywhere, from the USA (country number one in quantity of tourists and amount of revenues) to the Antarctica (that, in 1997, received 15 thousands holiday-makers, five times more than in 1991), the investments in tourism are growing (Roberts, 1998).

In spite of the importance of the tourism, it is still not recognized and supported with research and scholarships (Jafari, 1993). It still does not have the same treatment of the automobile, textile, oil or either agriculture industries. The crowded agenda of top decision-markers does not show tourism questions and problems with the frequency expected, considering the most important industry of the moment (Lipman, 1993). 
The tourism industry is still not studied seriously enough, creating a void of techniques related to the tourism activities. Many places could have larger and more profitable tourism industry, including some places that already have an intensive tourism. Natural attractions are very useful for developing a tourism industry, but this is not enough to develop tourism. Brazil is an example of a country that is full of natural attractions, but with a shy tourism in relation of its immense potentiality. As in many other countries, in Brazil, its is necessary to study and understand much better the tourism industry. It is a service industry and not a manufacturing industry where tangible values are more present allowing more Cartesian and predictable attitudes from government and investors as well.

The tourism industry needs to foresee the economic consequences of some of its actions and also of external actions. For instance, better meteorology systems should be developed to produce reliable forecasts for touristic events. It should must be possible to know which services will the tourists wish and also be able to conceive the ones that still do not exist. The competition in the tourism industry is strong at any phases of its production, since all the phases can offer directly a service to the consumer. The customer is so involved in his consumption that he desires to participate of any detail and steps of its production. The production is so important in this process, that it cannot just be a way to obtain a "better" service, but it also can be part of it.

The tourism firm should define the best way to compete and save its "limited energies": it is impossible to be the best in every area; sometimes it is necessary to focus in some directions. Competition means defining the distinctive competencies and the competitive priorities.

The distinctive competence consists of its work force (to have a flexible and well trained employee), its facilities (offices, stores and plants), its production and information system, its market knowledge, and its financial potential (to be able to finance the projects).

In the competitive priorities, the company should choose its direction between four polar directions: low cost, quality, time and flexibility. If the company chooses to compete with low cost, it will probably not be able to compete in the other directions. The notion that the industry will compete in one area does not mean incapacity to invest in other direction. Maybe it can decide that its priorities are two of the directions, or maybe a combination of the four directions, but it must find how to make itself prominent among its competitors.

It is fundamental to have a corporate strategy to define or redefine continuously the mission, the objectives, and the necessities of the firm. The objectives and the ways to reach them should be coherent with the market. In the past, the process of building and maintaining a market or a share business was basically a financial question. Nowadays, the financial availability is not enough, because capital is very volatile; knowledge is the key resource that can attract capital investments. A continuos analysis of market changes and future tendencies are also a must.

With a market analysis the firm is able to develop strategy and techniques to survive and to compete with the other companies in the tourism industry. One technique that has helped to develop the tourism is the yield management. Together with reservation systems networks, yield management is one of the keys to develop the tourism industry. 


\section{THE YIELD MANAGEMENT AND THE SERVICE INDUSTRIES}

A typical problem of many service industries, in particular the tourism industries, is how to deal with an uncertain demand for a service whose capacity is rather fixed and has a high fixed cost in relation to the variable cost. Airplanes seats in a flight, hotel rooms available at a given day, seats in a theater performance are just a few examples of this situation. How can someone decide when, how much and to whom sell, at what price, each unit of these limited services, if maximum profit is the objective?

Yield management is a class of methodologies for helping to cope with the above problem. Its use started intensively by the airline companies and, now, reached also the hotel and the rental car industries. This method is now starting to be used also by the rest of the service industry when limited capacity defines difficulties in maximizing the real market possibilities; examples are the entertainment industry (ex: stadium, park, theater and cinema), commercial centers, hospitals, schools, restaurants, the transport industry and the industries of tourism. Yield management is known as a way to maximize the revenues of an industry with limited capacity that considers the forecast of demand and that tries to spread the demand along the year. As it is able to treat groups individually, it can also maximize the revenue by segmenting the market in groups of clients, charging particular prices and offering services to groups of people that were excluded of the market (Lovelock, 1992).

Most of these companies, when applying the yield management technique, use the services of other industries in order to maximize their revenues, but do not maximize the revenue of the industries of the related chain of firms involved with their development. If the planning is such to maximize the whole chain gain, all the members of the related group will benefit, establishing a win-win game; in this circumstance, all within the industry will grow stronger and will further guarantee the success of its members.

These techniques are applicable in the long term, although frequently businesses tend to seek short-term advantages. Of course the management should take into account its effects on the entire supply chain. However, this is an involved issue because not all members of the chain will have its fair share of the total gain in the short term. The concept of maximization of revenues is nowadays taken as the maximization of the number of uses of the service, but considering the price tag per user; a good example is the advantage of having a half load of first class passengers in a plane as compared just with the full load of customers in the economic class (Scavarda, 2000).

Work with a service chain is very complex, since there are many different service industries. These industries vary from small industries, including companies operated by just one employee, to mega-industries. Regardless their dimension, they interact and compete among themselves. The dimension of the industries can influence its performance.

Nowadays, many groups are developing alliances following the idea of virtual chains. Most of these alliances are being realized by companies that deal with 
similar services, searching mechanisms to obtain lower cost of operation, or by different companies searching mechanisms for diversification, thus guaranteeing a lower risk and a higher efficiency.

\section{THE VIRTUAL ENTERPRISE}

It is need to study the tourism processes as a whole to be able to develop a sustainable tourism industry. It does not exist a clear cut border between service industry and manufacturing industry. Tourism is a service industry, but by sure, some concepts of the manufacturing industry will contribute to its development as it is also strongly linked to manufacturing industries. Actually, the definition of service industry and manufacturing industry exists just to help people to study and to develop these subjects. It is very difficult to find an industry that is a pure service or a pure manufacturing one. An important concept that will certainly prove as useful for service industries as it has already shown to be for manufacture is that of "supply chain management".

According to Pires (1998), supply chain management is a contemporary, strategic approach that manages manufacturing as a whole. The basic objective of this management is to maximize the synergy between all segments of the demand chain in order to serve the end consumer more effectively, by either reducing costs or enhancing value. In order to achieve this, companies have sought to align and join distinctive competencies in along the demand chain. Competition is now focused on productive chains instead of on companies. In other words, this means a change in the competitive model from the conventional "business unit" to "virtual business unit". This "virtual enterprise" can provide many of the benefits of vertical integration without losses in cost and flexibility (Vollmann and Cordon, 1996).

Understanding and managing effectively the supply chain of a tourism company is very different from a manufacturing company. The reason for this fact is that while in manufacturing many important supply chains resulted from a reduction of the vertical integration of large firms, in tourism they result from operational integration of very diverse and independents services. Furthermore, because services practically just exists in the presence of the customer, during the production and the post-purchase phases, many suppliers of the chain come in to direct contact with the consumer. Only during the pre-purchase phase the customer is in direct contact with the most downstream link - the tourism agent. To integrate the activities and facilitate the interactions among all the supply chain links and the consumer, technique far beyond the present reservation system networks is needed. 
It is important that tourism the supply chains develop an efficient operations management to deal with the complex system of services that contributes to the touristic service as if it were one single firm seeking its competition priorities.

The supply chain has also to define its positioning strategy (service focus, intermediate focus and process focus). In most of the cases, the service firm is a process-focused company. In other words, a company specialized in some specific kind of service. Each company of the supply chain can have different competitive priorities and position strategies, but the chain success requires well-defined objectives and all its sectors need to work together in order to achieve them.

To achieve its objective the chain should make decisions about its development. The company has to know how much control it must have over the chain and over the infrastructure necessary to develop its services. It has to know if it is going to sell its services or contract others to do it, if it will train its employees (not only the directly involved with the service, but also others like the security and the cleaner) or have others doing it or part of it, if it will have its own shuttle infrastructure or subcontract transport services, etc. Sometimes a company can trade large verticalization for some association or alliance with others industries. A global strategy (collaborative effort, joint venture or licensing of knowledge) must be very important in these situations (Krajewski and Ritzman, 1996).

\section{FINAL CONSIDERATIONS}

Services can be developed more efficiently with the establishment of partnerships among the members that belong to the same chain and with the use of techniques like yield management.

The use of the knowledge in managing the supply chain of manufacturing industries can also help the service industry to manage its chain. As a service industry, tourism must be understood in its peculiarities, but must also profit from developments obtained in manufacturing. Recent important researches for understanding and improving management of supply chains in manufacturing seem to be even more relevant to the tourism industry. Because of the complexity of the tourism supply chains, the needs of fast and reliable communication, coordination, and also because of the consumer involvement, the production process makes it extremely important to understand better the mechanisms and to implement them in a more efficient way. Even firms well prepared for competition with clear and effective strategies may not be sufficient for a tourism industry to prosper in a given country. The entire chain must have a well-established and coherent strategy.

Efficient allocation of resources is always an important factor in competition. To date, the only well disseminated technologies specifically developed for satisfying a specific tourism industry need are the networks of system reservations and yield management. The information technology plays a very important rule to link and tie the chain in order to benefit all its members and, mainly, the final consumer.

All in all, tourism is an industry that becomes more economically relevant. It must be understood and seriously studied so that new approaches for implementing and managing its supply chain must be developed. 


\section{REFERENCES}

1. Jafari, Jafar (May/1993): “Anchoring Tourism Projects on a Scientific Foundation - Prospects for Sustainable Tourism Development" The First International Conference on Investments and Financing in the Tourism Industry, Jerusalem,16-36.

2. Kurtz, David L., Clow, Kenneth E. (1998): "Consumer Expectations of Service" Services Marketing, John Wiley \& Sons, 64-96.

3. Krajewski, Lee J., Ritzman, Larry P. (1996): "Process Management" Operations Management Strategy and Analysis, Addison - Wesley Publishing Company, 93-138.

4. Lipman, Geoffrey (May/1993): "Generating Investments in the World's Largest Industry" The First International Conference on Investments and Financing in the Tourism Industry, Jerusalem, 9-15.

5. Lovelock, Christopher H. (1992): "Yield Management: A Tool for Capacity-Constrained Service Firms" Managing Service - Marketing, Operations, and Human Resources, Prentice-Hall International, 188-201.

6. Pires, Sílvio R.I. (1998): "Managerial implications of the modular consortium model in a Brazilian automotive plant", International Journal of Operations \& Production Management, Vol.18, No. 3, 221-232.

7. Roberts, Mark (January/1999): "Travel and Tourism" The Economist, 3-16.

8. Scavarda, Annibal José, et al. (April / 2000): "Tourism Industry: an Opportunity to the University" Third Triple Helix International, Rio de Janeiro, 271-276.

9. Vollmann, T. and Cordon, C. (1996): "Making supply chain relationship work", M2000 Business Briefing, IMD - Switzerland, No. 8, 4-5. 